\title{
Extracting principles for information management adaptability during crisis response: A dynamic capability view
}

\author{
Nitesh Bharosa \& Marijn Janssen \\ Delft University of Technology, The Netherlands \\ n.bharosa@tudelft.nl, m.f.w.h.a.janssen@tudelft.nl
}

\begin{abstract}
During crises, relief agency commanders have to make decisions in a complex and uncertain environment, requiring them to continuously adapt to unforeseen environmental changes. In the process of adaptation, the commanders depend on information management systems for information. Yet there are still numerous reports of situations in which commanders had to make decisions based on incomplete, outdated or incorrect information, indicating poor information quality. In many of these situations, poor information quality can be attributed to the information management process incapable of adapting to external (environmental) changes and internal (team) information needs. Using dynamic capability theory and the findings of a case study, this paper presents four principles for information management adaptability: (1) maintain and update team memory, (2) dedicate resources for environmental scanning, (3) maximize the number of alternative information sources and (4) integrate forecasting and back casting methods in the information management process.
\end{abstract}

\section{Introduction}

Decision-making during crisis response has proven to be a very difficult process to support with information management systems [e.g., 1, 2]. Scholars have suggested a range of contextual, organizational and technical factors to explain why this type of decision-making process is so difficult to support. For instance, Rao et al. argue [3] that crisis decision-making processes are constrained by response factors such as the response capacity, management expertise, limited situational awareness, and other human factors. In addition, the task environment is often extremely complex since there are many agencies and systems involved that interact in unpredictable ways [4]. Moreover, there is a tremendous urgency and time pressure surrounding the decision-makers [5]. Also uncertainty pertaining subsequent events, risks, resources and hazards dominate each round of the decision-making process $[6,7]$. Combined, all these factors require crisis response processes, including decisionmaking and information management processes, to adapt to changes in the response environment. In this way, information management processes may both support or impede decision-making adaptability. Here, information management is the iterative process of using information systems for acquiring, organizing, enriching and distributing information [8]. While aiming for enhanced adaptability, we recognize the multifaceted nature of this concept, meaning that it can be measured, enhanced or impeded on several levels of a socio-technical system. The scope of this paper is limited to information management adaptability, which we define as the ability to rapidly change existing or create new resources in order to align the internal information demand with external information supply and events. We consider adaptability as a nonfunctional requirement for information system design and use which should be treated as a soft-goal (i.e., achieved not absolutely but within acceptable limits) to be satisfied both by architects (during design) and users (during crisis). When targeting goals both in the design and use of information systems, The Open Group suggest using principles, which they define as "general rules and guidelines, that are intended to be enduring and seldom amended, that inform and support the way in which an organization sets about fulfilling its mission" [9].

Previous work by Turoff et al. [2] and Chen et al. [7] provides valuable principles for designing crisis response information management systems (hereafter CRIMS). Yet, many of these principles do not explicitly focus on enhancing adaptability during the use of CRIMS. Complementary to previous work, the objective of this paper is to extract and substantiate principles for information management adaptability during crisis response. In order to extract principles, we employ the dynamic capability view [10] since it allows us to describe the organization's (i.e., decision-making team's) ability to integrate, build, and reconfigure internal and external competences to address rapidly changing environments. This papers aims to contribute to existing literature in two ways: (1) provide an in-depth analysis of a CRIMS based on the dynamic capability view (2) extend the current set of principles with complementary principles for information management adaptability. The unit of analysis in this paper is a crisis decision-making team, which includes the commanders of relief agencies (i.e., police department, fire department and ambulance services). By commanders we mean strategic or tactical decisionmakers in leadership roles, either in the field or in remote command and emergency control centers.

This paper proceeds with a review of existing literature pertaining decision-making and information man- 
agement during crisis response, followed by a discussion on the need for adaptability. Next, we discuss the dynamic capability view, its underlying assumptions and its utility for enhancing adaptability. Then we present a case study on crisis response analyzed trough a dynamic capability view. Based on the case study findings four principles for information management adaptability are extracted and discussed. This paper concludes with a discussion of the findings, their limitations and avenues for further research.

\section{Information management in crisis deci- sion-making teams}

\subsection{Decision-making teams}

For the purposes of the paper, we work with the definition of crisis as stated by Turoff et al. [2]: "crises are high stress situations that require organizations to respond in a manner that is different from their normal operating procedures". A crisis is characterized by extreme threats to important values, intense time pressures, high stress, and the need for rapid, yet careful decisionmaking [11]. Responding to a crisis involves dealing with many hazards and risk, requiring the collaborative resources and capabilities of several relief agencies. Not one single agency involved has "it all" nor does any single commander possess the expertise in handling all of the crisis response areas. Usually each commander represents a specific relief agency that possesses one part of the resources needed to cope with a crisis event or hazard. Therefore, crisis response often takes place in team formations, including the commanders of various relief agencies (i.e., police, fire department and medical services). Commanders need to make both short and long-term decisions on mitigation and protective action, often in an atmosphere of uncertainty [5]. The commanders can communicate with several external teams, including emergency control personnel and field response teams. Information from these sources is disclosed rapidly, but is frequently incomplete. In addition, a particular incident may not be part of a commander's experience or knowledge base [1, 2]. All these factors complicate the decision-making environment of the decision-making team.

Depending on the country, such teams can be centralized, distributed or combinations of both. For instance in the Netherlands, the crisis response organization is predicated by law and follows an hierarchical structure with teams on a strategic, tactical and operation level [12]. Team members often have explicit roles and tasks, they also have access to different information sources and supporting CRIMS [13]. Often, commanders are primarily responsible for making many decisions and, therefore, do not have much time to devote to systematic information management. Therefore, many information management related tasks are delegated to dedicated roles such as information managers or control room personnel [12]. We discuss the process of information management next.

\subsection{Information management}

Information management is a relatively well-studied subject in the information systems domain and can be defined from various angles. Consequently, scholars have proposed several definitions and frameworks for information management [e.g., 14, 15]. Choo [8], for instance defines information management as "a cycle of processes that support the organization's learning activities: identifying information needs, acquiring information, organizing and storing information, developing information products and services, distributing information, and using information". For supporting each of these activities, information managers can employ one ore more information systems depending on the services they provide (supply). Often, this way of information management works fine in a single organization, operating in a moderately changing environment and with a predictable information supply and demand. However, during crisis response, the information supply and demand change continuously and are only partly predictable, often requiring information managers to adapt resources and flows in order keep decision-makers informed. Put differently, if an information manager fails to attain and transmit the required information, the whole response system will likely fail to adapt to the requirements of the risk environments in which it operates [4, 16]. The next section proceeds with an elaboration on adaptability.

\subsection{The need for adaptability}

Considering the crisis environment, scholars [e.g., 17] have characterized crisis response systems as open systems, indicating the blurred boundaries of the various systems components and their interactions with the environment. With the law of requisite variety Ashby [18] pointed out, that for a given state of the environment, an open system has to be able to respond in an adaptable way, otherwise the adaptability and the ability of the system to survive is reduced. Since this study, several scholars using different lenses have explicitly discussed the concept of adaptation, often focusing on strategic or organizational level adaptability. For instance, Chakravarthy [19] argues that the higher the level of adaptation, the higher is the environmental complexity that can be handled by the organization, or in this case the decisionmaking team. From an organization science perspective, adaptation is often the result of an ongoing negotiation between the organization and its environment [20]. Corbacioglu and Kapucu [21] analyzed the cultural, organizational, and technical capacity of five response systems and concluded that the availability of information, its 
exchange, and its distribution within and among organizational actors is critical for adaptation. Put differently, in order to match changing information demand and supply, information managers need to adapt their approach as the environment evolves and triggers new information needs or when new information arrives about the changed environment.

As stated in the introduction, the scope of this paper is limited to information management adaptability, which we define as the ability to rapidly change existing or create new resources in order to align the internal information demand with external information supply and events. Even is this focused definition adaptability remains a multi-dimensional concept, which can be improved or impeded by several other concepts depending on the type of disaster and the context in which it occurs. Therefore, it is difficult to specify a complete and exact list of concepts or variables that may enhance information management adaptability. Instead, we follow other scholars [e.g., 2, 11] who suggest the extract context independent principles that guide both architects and users in achieving higher level goals. Moreover, principles are particularly useful for designing information systems to be used in a multi-agency environment since each relief agency is interested in on other crisis elements and information resources. The next section discusses some principles presented in previous work.

\subsection{Design principles in previous work}

Van de Walle and Turoff [1] discuss the diverse and immense requirements and challenges for the design of information systems to be used in large scale emergency situations. Yet, there exists only a sparse body of literature on designing CRIMS. Housel et al. [11] were among the first to provide principles for the design and implementation of information systems for crisis management. However, their work predates the major advancements in information technology made in this decade. Later, Bui \& Sankaran [6] present some design considerations for a virtual information center that can both efficiently and effectively coordinate and process a large number of information requests for emergency management teams, focusing specifically on improving information system scalability. In 2004 Turoff et al. [2] published a set of general and supporting design principles and specifications for a dynamic emergency response management information system (DERMIS) by identifying design premises resulting from the use of the emergency management information system and reference index. They discussed a number of measures for enhancing information system performance in general. Taking a supply chain coordination view, Chen et al. [7] provide a set of design principles focusing on the coordination of the multi-agency response process. Accordingly, the principles suggested in their work target the improvement of coordination in crisis management situations.
Combined, the previously mentioned authors have made important contributions on designing CRIMS. Yet, none of these contributions explicitly target information management adaptability. Looking outside the body of knowledge in the crisis management domain, there is one strand of research that specifically focuses on identifying antecedents of adaptability. This strand of research uses dynamic capabilities theory [10]. Using this view, we can focus on finding antecedent for adaptability which we can use to extract principles.

\section{Dynamic capability theory}

\subsection{Background}

Dynamic capabilities represent a frequently studied concept in the strategic management literature [22] and builds on the resource-based theory [23]. In essence, the resource-based view (RBV) argues that organizations possess resources and capabilities [24] and trough their interactions yields superior performance. The RBV assumes that organizations can be conceptualized as bundles of resources that are heterogeneously distributed across various organizations, and that resource differences persist over time [22]. Based on some limitations of RBV [e.g., 10, 22] the dynamic capabilities view emerged to enhance the RBV [22]. While there is ongoing academic debate on the conceptualization of resources and dynamic capabilities [e.g., 25], we focus on applying (and not evaluating) the dynamic capabilities view on crisis response teams. The following subsections proceeds by substantiating the two main concepts in the dynamic capability theory: 1) resources and 2) dynamic capabilities [22], in the context of crisis response.

\subsection{Resources in crisis response teams}

A resource refers to an asset or input to production (tangible or intangible) that an organization owns, controls, or has access to on a semi-permanent basis [22]. For the purpose of this study we consider a crisis decision-making team as an organization, consisting of heterogeneous human resources, information resources and information-and communication technology (ICT) resources. Even though other resources need to be distinguished also, we continue with this conceptualization of resources. First and most important are the human resources. In crisis response, human resources have often been viewed as roles in teams since roles have always been a key part of any structured group communication process [25]. Roles are a key concept in the original EMISARI crisis management system [2]. Events and roles are the two concepts that professionals use for the planning, training, response, and evaluation of emergencies [26]. A role is a metaphor for the individual [8]. Examples of role in crisis response teams include team leader, information manager and press manager [12]. 
Another important resource in crisis response teams is information $[5,12,26]$, since information is the primary input and output of the decision-making process. Information resources are the core assets of transactions between roles. During crisis decision-making, information about the events which have occurred, their location, risks pertaining the effects, hazards and casualties are examples of core information resources that flow between roles and ICT resources. The range of information resources is quite wide, depending on the type of crisis. One can categorize information resources using multiple typologies, such as static or dynamic over time, relevant for a single agency (mono-disciplinary) versus relevant for all agencies (multi-disciplinary) and public (directly accessible) versus private information (not directly accessible). Since the relief agency commanders depend on information for decision-making, information quality is of primary importance [27]. Therefore, the quality of each information resource should be considered in each phase of the information management cycle, including the collection and dissemination of information.

A third important category of resources includes ICT services, since these are vital in extending our human capabilities to cope with either natural or manmade disasters [26]. ICT services have created the means to facilitate the sharing of information among various sub-units or teams by offering the advantage of instantaneous access to relevant information [4]. As a valuable resource, ICT should serve organizational goals by maintaining a robust information infrastructure to users involved in crisis response activities. Over the years, several categories of ICT services for crisis response have been developed [1], including geographical, early warning, training, recommender, incident management, tracking and tracing, and data storage systems. Accordingly, a myriad of ICT services became available for relief workers, including situation report generation, navigation and resource allocation [12]. According to Carver \& Turoff [26] there is still a tendency for technology to drive development, not fully taking into account the role of the new technology or its systemic impacts. This underlines the need for understanding the roles, information resources and ICT services in conjunction with each other.

\subsection{Dynamic capabilities}

It is important to distinguish between capabilities and dynamic capabilities in order to appreciate the merits of each [25]. Winter [28] defines a capability as "a high level routine that, together with its implementing input flows, confers upon an organization's management a set of decision options for producing significant outputs of a particular type". Dynamic capabilities on the other hand, are geared toward effecting organizational change; they are essentially strategic in nature and, therefore, define the firm's path of evolution and development. Teece et al. [10] define dynamic capabilities as "the ability to integrate, build, and reconfigure internal and external competences to address rapidly changing environments". Hence, by definition, dynamic capabilities involve adaptation and change, because they build, integrate, or reconfigure other resources and capabilities. Dynamic capabilities help organizations to change their resource configurations in order to cope with a changing environment. Accordingly, dynamic capabilities can be considered as antecedents of adaptability and they should be considered in the design and use CRIMS (i.e., using principles). According to Eisenhard \& Martin [22] there is no universal set of dynamic capabilities since organizations and the velocity of their environments are different. Yet, these authors suggest that there are some categories for organizing dynamic capabilities. For instance, some dynamic capabilities integrate resources within the organization, enabling value creation and learning. There are also dynamic capabilities that focus on diversifying and complementing resources in order to maintain redundancy and continuity. Other dynamic capabilities focus on the generation of new or the reconfiguration of existing resources within or between organizations. There are also dynamic capabilities that promote learning through resource sharing. Still other dynamic capabilities are related to the gain resources from the environment. While recognizing that other categories may prove useful in future analyses, we use the categories of resources and dynamic capabilities discussed earlier for organizing our case study on crisis response.

\section{Explorative case study}

\subsection{Overview and background}

The case studied is on a recent tactical level crisis response exercise in Oostflakkee, a mid-sized municipality in the Netherlands. The purpose of the exercise was to train the Mayor and the team of commanding officers in decision-making and information management during a large crisis situation in the municipality. The process of decision-making and information management was rehearsed, while the crisis events and the effects of the decisions were simulated by a counter-playing team. The reason we chose to employ this case study for this research is that the tactical response team is focused both on decision-making (what do we command the field units to do?) and information management using a CRIMS. The next table provides a summary of the exercise characteristics.

Table 1: Characteristics of the exercise

\begin{tabular}{|l|l|}
\hline Objective & $\begin{array}{l}\text { Exercise decision-making and infor- } \\
\text { mation management during crises and } \\
\text { evaluate the use of CEDRIC. }\end{array}$ \\
\hline Authority/ & Tactical level of response (the stra- \\
\hline
\end{tabular}




\begin{tabular}{|l|l|}
\hline level & $\begin{array}{l}\text { tegic and operational levels were si- } \\
\text { mulated by the counter play). }\end{array}$ \\
\hline $\begin{array}{l}\text { Participating } \\
\text { agencies }\end{array}$ & $\begin{array}{l}\text { Police Department, Fire Department, } \\
\text { Ambulance Services, Municipality } \\
\text { and Department of Justice. }\end{array}$ \\
\hline $\begin{array}{l}\text { Number of } \\
\text { participant }\end{array}$ & $\begin{array}{l}\text { 9 in main decision making team, 3 in } \\
\text { the control room and 2 in the counter } \\
\text { playing team. }\end{array}$ \\
\hline Schedule & May 15 2009, from 8:15-13:00 \\
\hline $\begin{array}{l}\text { ICT } \\
\text { resources }\end{array}$ & $\begin{array}{l}\text { CEDRIC, C2000, MS WORD, two } \\
\text { laptops, printer and projection bea- } \\
\text { mer. }\end{array}$ \\
\hline Setting & Indoor computer aided simulation. \\
\hline Scenario & Airplane crashes on a local school. \\
\hline
\end{tabular}

The table lists the main characteristics of the exercise. Next, we discuss our approach for studying this exercise and the findings.

\subsection{Objective and method}

Our objective with the case study was twofold. First, we wanted to substantiate the categories of resources and of dynamic capabilities listed in the previous section. Second, we wanted to describe a foundation for synthesizing dynamic capabilities that were (or would have been) necessary for information management adaptability. Given the exploratory nature of our research objective, we have chosen for a qualitative research method that combines ethnography and case study research. We wanted to start from a work situation where actual practitioners used their ordinary methods in order to be able to work out propositions, which we can test in an experimental situation in future research. According to Yin [29], case study research is most appropriate in scenarios where the research is exploratory in nature and focuses on contemporary events that occur beyond control of the investigator. The strength of this approach is the in-depth and first hand understanding the researcher obtains. Thanks to previous collaboration with the exercise organizers, we were allowed to observe a crisis management simulation exercise, involving script based role play with real relief workers and realistic crisis events.

We observed the exercise in a team of three observers. Prior to the simulation, we were informed on the exercise setup, structure, scenario and participants. During the exercise, two of the three observers took notes, while the third observer video recorded the events. The exercise was observed using a predefined observation protocol, including blank tables for the recording of: roles (table 3), information resources and their quality attributes (table 4) and ICT services (table 5). After the exercise, we were allowed to listen during the plenary briefing of the participants. The log files (in situation report format) of the ICT service used (CEDRIC) were emailed to us afterwards.

\subsection{Crisis scenario and choreography}

The exercise had the form of a role play simulation using a crisis scenario. The events and conditions in the scenario were defined in a script format. The script of the exercise was only known to the exercise organizers and by the authors of this paper. Depending on the location of the decision-making team in the script, new messages containing event or context information were provided to the participants, either via mobile phones, radio phones, paper instructions or as notifications in CEDRIC. The scenario rehearsed was developed by a team of experts, including experienced relief workers. The scenario contained multiple complex events, ultimately evolving into a second to largest disaster category in the Netherlands. The disaster starts with the crash of a passenger airplane on a school building in the municipality at 8:45 am, fifteen minutes before the first classes actually start. The idea was that this would initially create confusion about the number of students that were at the school. Another major uncertainty was about the type of chemicals stored in the chemistry laboratory of the school. As the laboratory was just outside of the centre of the plane crash, the fire department commander was reluctant to send in his units before he was sure that the chemistry lab would not explode.

During the exercise four rooms were used: (1) the decision-making room, (2) the counter play room, (3) the crisis control room (911 office) and (4) the press conference room (first floor). These rooms were in the same building but completely isolated. The following figure illustrates the set up of the exercise.

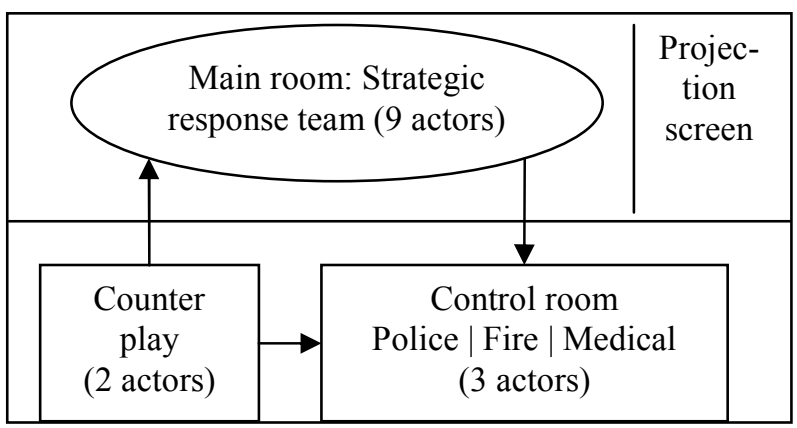

Figure 1: Exercise choreography

This figure illustrates the choreography of the teams and the number of actors during the exercise. Next we discuss the decision-making process during the exercise.

\subsection{Decision-making rounds}

The exercise was divided in five plenary decisionmaking rounds and four action rounds in which the decision-makers were allowed to go back to their (simulated) control rooms. In addition, the Mayor was allowed to speak to the press during the action rounds. For this exercise a group of five media and news reporting students 
were used to mimic real paparazzi. At the start of the exercise the Mayor requested the team members to turn off their radios, phones and pagers since these would interrupt the meetings. Each decision-making round took between 25 and 30 minutes. Each action round took about 10 to 15 minutes. The following table provides an overview of the decision-making rounds.

Table 2: Decision-making rounds

\begin{tabular}{|c|c|}
\hline $\begin{array}{l}\text { 08:15-08:30 } \\
\text { (simulated) }\end{array}$ & $\begin{array}{l}\text { Airplane crashes into a public school, } \\
\text { call to Control Room (911) comes in } \\
\text { and first responders are dispatched to } \\
\text { the scene }\end{array}$ \\
\hline $08: 45$ & $\begin{array}{l}\text { Start of incident. Alarm is send to relief } \\
\text { workers and commanders. Activation } \\
\text { of the Municipal strategic crisis re- } \\
\text { sponse team }\end{array}$ \\
\hline 09:00 & $\begin{array}{l}\text { n-making round 1: Formation of } \\
\text { nicipal strategic crisis response } \\
\text { troductions }\end{array}$ \\
\hline 09:30- & ound 1 \\
\hline $9: 40-10: 05$ & $\begin{array}{l}\text { Decision-making round 2: Discussion } \\
\text { on actions and information received } \\
\text { from the field units, identifying infor- } \\
\text { mation needs and allocation of infor- } \\
\text { mation gathering tasks }\end{array}$ \\
\hline $10: 0$ & $\begin{array}{l}\text { Action round 2, press conference by the } \\
\text { Mayor }\end{array}$ \\
\hline $10: 3$ & $\begin{array}{l}\text { Decision-making round 3: Response } \\
\text { efforts, help from other municipalities }\end{array}$ \\
\hline 11: & ct \\
\hline $11: 15$ & $\begin{array}{l}\text { king round } 4: \text { Next day: } \\
\text { the recovery efforts }\end{array}$ \\
\hline $11: 45-12: 00$ & $\begin{array}{l}\text { Action round 4, press conference by the } \\
\text { Mayor }\end{array}$ \\
\hline $12: 00-12.30$ & $\begin{array}{l}\text { Decision-making round 5: Aftercare, } \\
\text { coordination of the recovery process }\end{array}$ \\
\hline $12.30-13.00$ & Plenary evaluation and closing \\
\hline
\end{tabular}

This table provides an overview of the exercise structure. We discuss the actors and roles next.

\subsection{Human resources}

In the exercise, there were 14 participants, which were assigned different roles based on their profession. The following table list the roles observed.

Table 3: Actors and roles in the simulation

\begin{tabular}{|l|l|}
\hline Actor & Role(s) \\
\hline Mayor & $\begin{array}{l}\text { Process leader, team captain, com- } \\
\text { munication to external parties }\end{array}$ \\
\hline Chief of police & $\begin{array}{l}\text { Allocation of police resources, fo- } \\
\text { cus on law and order }\end{array}$ \\
\hline $\begin{array}{l}\text { Chief of fire } \\
\text { department }\end{array}$ & $\begin{array}{l}\text { Allocation of fire department re- } \\
\text { sources, focus on mitigation of fire }\end{array}$ \\
\hline
\end{tabular}

\begin{tabular}{|l|l|}
\hline & and evacuation of victims \\
\hline $\begin{array}{l}\text { Chief of ambul- } \\
\text { ance services }\end{array}$ & $\begin{array}{l}\text { Allocation of ambulance services } \\
\text { and coordination of medical aid }\end{array}$ \\
\hline $\begin{array}{l}\text { Secretary of the } \\
\text { Mayor }\end{array}$ & $\begin{array}{l}\text { Information manager: 1) receiver } \\
\text { of external situation reports, 2) } \\
\text { generation of internal team situa- } \\
\text { tion reports, 3) projection of situa- } \\
\text { tion reports }\end{array}$ \\
\hline $\begin{array}{l}\text { Municipal } \\
\text { emergency } \\
\text { officer }\end{array}$ & $\begin{array}{l}\text { Provision of municipal plans per- } \\
\text { taining risk and crisis management, } \\
\text { supporting information manager }\end{array}$ \\
\hline $\begin{array}{l}\text { Chief of medi- } \\
\text { cal services }\end{array}$ & $\begin{array}{l}\text { Focus on the treatment of victims } \\
\text { on the spot and transport to nearby } \\
\text { officers }\end{array}$ \\
\hline $\begin{array}{l}\text { Department of } \\
\text { Justice officer }\end{array}$ & $\begin{array}{l}\text { Support in terms of legal affairs } \\
\text { and provide advice on legislation } \\
\text { and procedures }\end{array}$ \\
\hline Press officer & $\begin{array}{l}\text { Information management towards } \\
\text { the press, spotting information pub- } \\
\text { lished by journalists (radio, televi- } \\
\text { sion, Youtube) }\end{array}$ \\
\hline $\begin{array}{l}\text { Control room (3 } \\
\text { actors) }\end{array}$ & $\begin{array}{l}\text { Information management support } \\
\text { to the respective relief agencies }\end{array}$ \\
\hline $\begin{array}{l}\text { Counter play (2 } \\
\text { actors) }\end{array}$ & $\begin{array}{l}\text { Provide counter play to the other } \\
\text { actors based on the exercise script }\end{array}$ \\
\hline
\end{tabular}

The table shows that a number of actors played different roles. These roles are not substitutable and interchangeable, as each focus on their own domain. Furthermore, there might be some overlap between information resources. For instance, information about casualties might come from fire department and police (observed in field) medical services (number in ambulance/hospital) and press (external sources). The various commanders in the team were unaware of the information related roles in the team, and because there were no arrangements settled prior to the meetings, information was shared according to the opportunity rather than its relevance. In terms of the information management role, the office secretary who fulfilled to role of information manager was more often focused on listening, typing and depicting information on the central projection screen. This person did not once during the exercise reflect on the quality of the information she was portraying to the team and which would be send to the other (simulated) echelons. Often, her role was more a note-taker than as an information manager.

\subsection{Information resources and quality issues}

The use of several information resources was observed during the exercise. Situation reports were the main information resources during the exercise, especially since they consisted of brief information of what the other teams know (external information) and what this team knows (internal). Other information resources in- 
cluded digital and paper maps, documents and short paper messages brought in by control room members. Events and information resources that spurred uncertainty in the decision-making process included:

- Identification of airplane passengers

- Registration and monitoring of victims who were being transferred to different hospitals

- Risk objects in the area (chemistry lab on school)

- Disaster tourists from the neighboring area

- Hospitals and emergency nursery locations

- Guidance and support facilities for family members

- Press conferences: which information should be shared (e.g., victims)

- The presence of several national and private investigation bureaus on the scène

- Air traffic control and continuation

- Traffic jams and disaster area control

- Release of and measurement of asbestos in the air

This list shows some of the main events that triggered information management activities in the team. Each information resource had various quality attributes and can be rated differently on each of them. We observed that regarding many of the information resources, their quality was poor. The following table presents some of the information quality issues that we recorded.

Table 4: Examples of information quality issues

\begin{tabular}{|l|l|}
\hline Attribute & Example \\
\hline Completeness & $\begin{array}{l}\text { Information about the events and risk } \\
\text { objects was incomplete in each round }\end{array}$ \\
\hline Relevancy & $\begin{array}{l}\text { It was difficult to judge which informa- } \\
\text { tion was relevant for one specific agency } \\
\text { (mono-disciplinary) and which informa- } \\
\text { tion was relevant for the entire group } \\
\text { (multi-disciplinary) }\end{array}$ \\
\hline Timeless & $\begin{array}{l}\text { Information about the number of passen- } \\
\text { gers and the number of students only } \\
\text { became available at round 3, which was } \\
\text { too late according to the team members }\end{array}$ \\
\hline Consistency & $\begin{array}{l}\text { The number of students on school was } \\
\text { inconsistent throughout the simulation. }\end{array}$ \\
\hline Accessibility & $\begin{array}{l}\text { The team was unable to directly access } \\
\text { information about the passengers, the } \\
\text { students and the flammable or toxic ma- } \\
\text { terials at the school }\end{array}$ \\
\hline Reliability & $\begin{array}{l}\text { Information about the risk of asbestos } \\
\text { release in the air was unreliable and even } \\
\text { unnecessary precautions were taken. }\end{array}$ \\
\hline Correctness & $\begin{array}{l}\text { The nationality of three foreign passen- } \\
\text { gers was incorrect; the Mayor was even } \\
\text { corrected by the press }\end{array}$ \\
\hline
\end{tabular}

Table 4 summarizes a few of the many information quality issues we observed. Some of these information quality issues had clear impacts on the decision-making process, including delay of decision making due to incomplete information about hazards or inaccurate information about the chemical in the chemistry lab.

\subsection{ICT resources and enabled capabilities}

The main ICT resource in the exercise was CEDRIC. This resource is a web-based application for vertical (between the strategic, tactical and operational levels) and horizontal (between various relief agencies) information sharing. The display of this application was projected on the main screen in the room. The main operators of CEDRIC included the information manager, the control room personnel and the counter play (simulated messages into the system). Prior to this exercise, these operators have followed an introduction class on operating this system. Using CEDRIC, these operators were able to view and generate situation reports, visualize hazards or resources on a digital map (plotting), send emails to other teams on response levels and search through stored files. The following table summarizes the main capabilities enabled by CEDRIC.

Table 5: Capabilities enabled by CEDRIC

\begin{tabular}{|l|l|}
\hline Capabilities & Description of use in the case \\
\hline $\begin{array}{l}\text { Situation report } \\
\text { generation }\end{array}$ & $\begin{array}{l}\text { Situation reports were generated and } \\
\text { shared with other echelons. }\end{array}$ \\
\hline $\begin{array}{l}\text { E-mailing and } \\
\text { messaging }\end{array}$ & $\begin{array}{l}\text { CEDRIC was used for sending and } \\
\text { receiving emails, for instance includ- } \\
\text { ing situation reports (to the control } \\
\text { room). }\end{array}$ \\
\hline $\begin{array}{l}\text { Situation plot- } \\
\text { ting }\end{array}$ & $\begin{array}{l}\text { The information manager was able to } \\
\text { view detailed 3 dimensional maps of } \\
\text { the location and could add/change } \\
\text { layers of information on the map. } \\
\text { This service was only used as a print } \\
\text { which was distributed among the } \\
\text { team members. }\end{array}$ \\
\hline $\begin{array}{l}\text { Finding contact } \\
\text { information }\end{array}$ & $\begin{array}{l}\text { CEDRIC includes a telephone and } \\
\text { address book focused on relief work- } \\
\text { ers and experts, but the information } \\
\text { manager did use this service }\end{array}$ \\
\hline
\end{tabular}

From this table we can conclude that the capabilities enabled though ICT resources are basic and do not allow for integrating other (external) resources. For instance, CEDRIC did not enable the information manager to validate information or accessing information beyond what was stored in the system. In the next section we continue with a discussion on the case study findings. 


\section{Findings: extracting four principles in- formation management adaptability}

The case study allowed for an in-depth analysis of roles, information resources and ICT resources, specifically in the context of crisis response. From this case study we can conclude that even though several resources (e.g., information manager, CEDRIC) and capabilities (e.g., situation report generating, plotting) were in place, the information management process lacked dynamic capabilities. In other words, the decision-making team was unable to integrate, build, and reconfigure internal and external resources to accommodate emerging information needs (internal) and external developments.

The principles that we present below are based on three sets of inputs. First, and most influential, they are the lessons that we have learned from the case study. Second, we have attempted to integrate what other scholars of adaptability have reported and suggested. Third, we have incorporated what we know in general about designing and operating CRIMS. We have synthesized these three sets of inputs to produce the following four principles for information management adaptability.

\subsection{Principle 1: Maintain and update team memory}

In the case study we observed that there was no directly exploitable library or information storage system in which the information flowing into or out of the decision-making team could be stored and organized. In other words, it was difficult to maintain and update team level memory, which is often considered to be one of the antecedents of adaptability [20]. As a consequence, some information resources were repeatedly requested (i.e., location of the incident) leading to unnecessary utilization of the information manager or the control room. We do not consider the projected situation report (on the projection screen) as a library for two reasons: (1) they contained either incomplete or outdated information from other teams (i.e., strategic level) for internal decisions that are being taken at the moment supreme and (2) team members were unable to exploit knowledge gained from previous (real) disasters in the area.

Based on information processing theory, Galbraith [30] suggests that a team can be made to handle higher environmental complexity if its repertoire of information is expanded continuously and its ability to exploit such repertoire is correspondingly improved. Lee and Bui [31] also recognized the need for such a dynamic capability and suggest that the design of any crisis response system should support some form of organizational memory component and should somehow be able to capture both tacit and explicit knowledge about how prior crisis situations were dealt with. Assigning someone outside of the core team to the role of periodically ensuring that information updates are included in the library and displays are updated would serve as an additional check during intense, highly dynamic situations.

\subsection{Principle 2: Dedicate specific resources for environmental scanning}

We observed that the decision-making team was often blindsided during their meetings. Especially since mobile phone or radio communication during the meetings was prohibited by the Mayor, the commanders of the respective agencies were unable to attain situational updates. As a result they were often unaware of new developments in the environment (i.e., release of asbestos) and were unable to adapt their decisions to accommodate new developments. Many developments could have been captured and brought into the team if some of the team's resources were dedicated to scanning the environment. Environmental scanning is the internal communication of external information about issues that may potentially influence an organization's decision-making process [32]. The idea is that through consistent monitoring of external influences, decision-making teams can shape their own internal processes to reflect necessary and effective responses. Environmental scanning includes a continuous flow of assessing the organization, adapting, developing a strategic plan and assessing again [8]. Albright [32] adds that environmental scanning is not a stagnant process, it should be constant and ongoing in order to maintain a preparative stance as environmental influences arise. The process of understanding the match between external influences and internal responses assists in adjusting organizational structure and strategic plans that are designed to be more effective and flexible to changing external conditions [8]. A challenge here is that the team leader (Mayor) explicitly requested not to make or maintain voice communication during the meetings. One way for dealing with this could be to centrally post and display new or incoming information that is potentially crucial for decision-making (e.g., using the central projection screen) during the meetings.

\subsection{Principle 3: Maximize the number of al- ternative information sources}

Relief workers in general and in this case in particular, tend to depend on one or two sources for their information. In the case study we found that often these sources are internal (agency specific) sources such as control rooms; with a few exceptions (e.g., the information manager used CEDRIC to find location maps). The idea is that the control room is the easiest to access and most reliable source of information. However, we observed that in many cases the control room was not the source of information, but an intermediary in the information flows from source to sink. In practice, the control room has many other tasks during crises, including the provision of information to worried civilians, physical 
resource monitoring and coordination and so on. As a result, controls rooms are often too busy to act as dedicated intermediaries for decision-making teams. In this case, we observed situations in which the commanders were faced with incomplete or inaccurate information coming from the control rooms. As a result, the commanders either pulse each other for more information or just wait for more information before taking action (or as one commander said: "no information is better than wrong information"). A flipside to this strategy is that time is very limited and that delayed decision-making due to information shortage may lead to even more complications. In other words, single source dependency limits the decision-making team's ability to improve the quality of the available information, and consequently the ability to adapt the information management process. An alternative would be to enable the information manager (i.e., using CEDRIC) to prompt other information sources which are either known or unknown for additional information and try to "triangulate" the various information resources in other to get a more complete or accurate set of information.

\subsection{Principle 4: Integrate forecasting and back casting methods in the information man- agement process}

The team of commanders led by the Mayor was primarily focused on asking two questions: (1) what do we know and (2) what do we need to do? We observed that the information manager was either trying to type the reactions of the commanders in the situational report (using CEDRIC) or search for information resources requested by the Mayor. Consequently, we did not observe that any one in the team was forecasting (e.g., preparing for questions like: what kinds of information do we need in case the main hazard was to escalate?) or back casting the worst case scenario (i.e., assuming the chemistry lab explodes and the entire school will be in flames, which events would have led to this situation and what information resources might become of potential interest? We argue that dynamic capabilities such as forecasting and back casting information resource needs would have enabled the information management process to better prioritize and reconfigure resources in order to adapt to future information needs (i.e., risks of asbestos release).

\section{Conclusions and further research}

This paper studies the adaptability of information management processes in crisis response, particularly focusing on extracting principles for information management adaptability. For the purpose of this paper we defined adaptability as the ability to rapidly change existing or create new resources in order to align the internal information demand with external information supply and events. Our review of previous work indicated that the current set of principles needed to be complemented with principles focusing on enabling information management adaptation. Using a dynamic capability view, we studied the resources in a crisis management exercise, allowing us to extract four principles for information management adaptability. Each principle is focused on creating dynamic capabilities, which are necessary (but not sufficient) for information management adaptability. The principles we propose are formulated as prescriptive and directive guidelines for CRIMS architects and users. The principles include: (1) maintain and update team memory, (2) dedicate resources for environmental scanning, (3) maximize the number of alternative information sources and (4) integrate forecasting and back casting methods in the information management process. We argue that such generic principles are particularly valuable for guiding architects and users in heterogeneous multi-agency environments. Because principles are generic and non-solution constraining, they do not force architects to work with standards or solutions which do not fit their agency's needs. This level of freedom is especially important when designing CRIMS which ought to be used by multiple agencies in a crisis response team or network.

We underline that despite its merits, information management adaptability should not be considered as an panacea for solving all the problems experienced during this case study, or crisis response in general. Adaptation of information management is a demanding task in terms of establishing effective communication channels between relief workers on multiple response levels, as well integrating CRIMS as a natural part in the daily operations of the relief agencies. We consider it to be an important responsibility of relief agencies to continuously support training and stimulating the use of CRIMS as well as creating the dynamic capabilities for adaptation.

There are two main limitations that should be considered when interpreting the conclusions of this research. First, we only studied one case on crisis response, focusing on a specific context of CRIMS use. Since we have only looked at one case, albeit extensively, the findings can only be analytically generalized based on the distinguished characteristics [29]. Therefore, we encourage scholars to investigate more and other types of crises case studies in further research. A second limitation is that we did not study the process of developing the CRIMS system (in this case CEDRIC) which was used. For instance, action research on the development of CRIMS would have provided more detailed understanding on the principles used for its design. We recommend longitudinal research on CRIMS design processes, particularly focusing on ways to extract the design knowledge from the architects. 


\section{References}

[1] B. van de Walle and M. Turrof, "Decision support for emergency situations" Information Systems and EBusiness Management, vol. 6, pp. 295-316, 2008.

[2] M. Turoff, M. Chumer, B. Van De Walle, and X. Yao, "The Design of a Dynamic Emergency Response Management Information System (DERMIS)." Journal of Information Technology Theory and Application (JITTA), vol. 5, pp. pp. 1-35., 2004.

[3] H. R. Rao, V. S. Jacob, and F. Lin, "Hemispheric specialization, cognitive differences, and their implications for the design of decision support systems," MIS Quarterly, vol. 16, pp. 145-151, 1992.

[4] S. Celik and S. Corbacioglu, "Role of information in collective action in dynamic disaster environments," Disasters, Forthcomming paper, 2009.

[5] A. Boin, P. 't Hart, E. Stern, and B. Sundelius, The Politics of Crisis Management: Public Leadership Under Pressure: Cambridge University Press, 2005.

[6] T. X. Bui and S. R. Sankaran, "Design considerations for a virtual information center for humanitarian assistance/disaster relief using workflow modeling," Decision Support Systems, vol. 31, pp. 165-179, 2001.

[7] R. Chen, R. Sharman, H. R. Rao, and S. Upadhyaya, "Design Principles for Emergency Response Management Systems," Journal of Information Systems and e-Business Management, vol. 5, pp. 81-98, 2007.

[8] C. W. Choo, Information Management for the Intelligent Organization. The Art of Scanning the Environment, third ed. Medford, New Jersey: Information Today/Learned Information 2000 .

[9] TOGAF, "The Open Group Architecture Framework. Version 8.5, Enterprise Edition," 2004.

[10] D. Teece, G. Pisano, and A. Shuen, "Dynamic Capabilities and Strategic Management," Strategic Management Journal, vol. 18, pp. pp.509-533, 1997.

[11] T. J. Housel, O. El Sawy, and P. F. Donovan, "Information Systems for Crisis Management: Lessons from Southern California Edison " MIS Quarterly, vol. 10, pp. 389-400, 1986.

[12] N. Bharosa, Y. Lee, and M. Janssen, "Challenges and Obstacles in Information Sharing and Coordination during Multi-agency Disaster Response: Propositions from field exercises," Information Systems Frontiers, vol. forthcoming special issue on Advances in Information Systems for Disaster Management, 2009.

[13] H. Artman, "Situation awareness and co-operation within and between hierarchical units in dynamic decision making," Ergonomics, vol. 42, pp. 1404-1417, 1999.

[14] C. W. Choo, B. Deltor, P. Bergeron, and L. Heaton, "Working with information: Information management and culture in a professional service organization.," Journal of Information Science vol. 32, pp. 491-510, 2006.

[15] P. Checkland and S. Holwell, "Information management and organizational processes: an approach through soft systems methodology," Information Systems Journal, vol. 3, pp. 3-16, 1993.
[16] L. Comfort, K. Ko, and A. Zagorecki, "Coordination in Rapidly Evolving Disaster Response Systems: the role of information," American Behavioral Scientist, vol. 48, pp. pp. 295-313, 2004.

[17] L. Comfort, Y. Sungu, D. Johnson, and M. Dunn, "Complex Systems in Crisis: Anticipation and Resilience in Dynamic Environments," Journal of Contingencies and Crisis Management, vol. 9, pp. pp.144-159, 2001.

[18] R. W. Ashby, "Requisite variety and its implications for the control of complex systems," Cybernetica, vol. 1, pp. 83-99, 1958.

[19] B. S. Chakravarthy, "Adaptation: A Promising Metaphor for Strategic Management," The Academy of Management Review, vol. 7, pp. 35-44, 1982.

[20] J. March, "Exploration and exploitation in organization-al learning," Organization Science, vol. 2, pp. 71-87, 1991.

[21] S. Corbacioglu and N. Kapucu, "Organisational Learning and Selfadaptation in Dynamic Disaster Environments " Disasters, vol. 30, pp. pp.212-233, 2006.

[22] K. Eisenhardt and J. Martin, "Dynamic Capabilities: What Are They?," Strategic Management Journal, vol. 21, pp. pp.1105-1121, 2000.

[23] B. Wernerfelt, "A Resource Based View on the Firm," Strategic Management Journal, vol. 5, pp. pp.171-180, 1984.

[24] N. Ahituv, M. Igbaria, and A. Sella, "The effects of time pressure and completeness of information on decision making," Journal of Management Information Systems, vol. 153-172, p. 2, 1998.

[25] M. Wade and J. Holland, " Review: The Resourcebased View and Information Systems Research: Review, Extension, and Suggestions for Future Research," MIS Quarterly, vol. 28, pp. 107-142, 2004.

[26] G. A. Bigley and K. H. Roberts, "The incident command system: High reliability organizing for complex and volatile task environments," Academy of Management, vol. 44, pp. pp.1281-1300, 2001.

[27] N. Bharosa, B. van Zanten, A. Zuurmond, and J. Appelman, "Identifying and confirming information and system quality requirements for multi-agency disaster management," in Proceedings of the 6th International Conference on Information Systems for Crisis Response and Management (ISCRAM), 2009.

[28] S. G. Winter, "Understanding Dynamic Capabilities," Strategic Management Journal Special Issue: Why Is There a Resource-Based View? Toward a Theory of Competitive Heterogeneity vol. 24, pp. 991-995, 2003.

[29] R. K. Yin, Case Study Research: Design and Methods Third edition ed. Thousand Oaks, CA: Sage, 2003.

[30] J. Galbraith, Designing complex organizations. Reading MA: Addison- Wesley, 1973.

[31] J. Lee and T. Bui, "A Template-based Methodology for Disaster Management Information Systems," in 33rd Hawaii International Conference on System Sciences Hawaii: IEEE, 2000.

[32] K. S. Albright, "Environmental Scanning: Radar for Success," Information Management Journal, vol. 38, pp. 3845, 2004. 